\title{
Carbetocin Versus Oxytocin for Prevention of Postpartum Hemorrhage in Cesarean Section
}

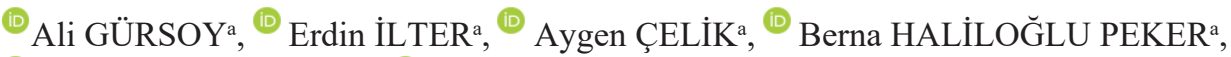

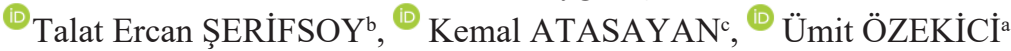 \\ ${ }^{a}$ Department of Obstetrics and Gynecology, Maltepe University Faculty of Medicine, İstanbul, TURKEY \\ ${ }^{b}$ Department of Anesthesiology and Reanimation, Maltepe University Faculty of Medicine, İstanbul, TURKEY \\ 'Department of Obstetrics and Gynecology, Bezmiâlem University Faculty of Medicine, İstanbul, TURKEY
}

This research article was produced from the thesis with the heading of "Comparison of efficiency and side effect profile of carbetocin and oxytocin in patients who underwent caesarean section under general anesthesia".

\begin{abstract}
Objective: We aimed to compare the haemodynamic effects of carbetocin and oxytocin in preventing postpartum hemorrhage during cesarean delivery. Material and Methods: This study was conducted retrospectively in a university hospital. Women in the carbetocin group $(n=42)$ and women in the oxytocin group $(n=78)$ were evaluated in terms of changes in hemoglobin level, hematocrit level, uterotonic need, urine output, blood transfusion requirement, hospital stay, postoperative fever and need for peripartum hysterectomy. Results: There was not statistically significant difference between their additional uterotonic need but preoperative and postoperative $24^{\text {th }}$ hour hemoglobin reduction, calculated estimated blood loss and platelet count diminution percentage were significantly lower in the carbetocin group compared to oxytocin group ( $p=0.044 ; p=0.042 ; p=0.004$, respectively). Besides that, the rate of blood loss of $\geq 500 \mathrm{~mL}$ was lower but not significantly different in patients receiving carbetocin compared to those using oxytocin $(\mathrm{p}=0.059)$ and the duration to reach $1,500 \mathrm{cc}$ urine output of carbetocin group was significantly lower than the oxytocin group $(\mathrm{p}=0.001)$. Conclusion: Carbetocin appears to be more effective in the hemoglobin reduction, platelet reduction and calculated estimated blood loss. In addition, another advantage of carbetocin is that it has lower negative effects on urine output than oxytocin. It is noteworthy that carbetocin administration can prevent postpartum hemorrhage in appropriate cases.
\end{abstract}

Keywords: Carbetocin; oxytocin; postpartum hemorrhage

Blood loss of $500 \mathrm{~mL}$ or more within 24 hours after childbirth is defined as postpartum hemorrhage (PPH) by the World Health Organization. ${ }^{1}$ On the other hand, The American College of Obstetricians and Gynecologists defined PPH, as a cumulative blood loss of greater than or equal to $1,000 \mathrm{~mL}$ or blood loss accompanied by signs or symptoms of hypovolemia within 24 hours after the birth process, regardless of route of delivery. ${ }^{2} \mathrm{PPH}$, one of the leading causes of maternal deaths in low-income countries is the main cause of almost one-fourth of deaths worldwide. ${ }^{3,4}$

In the active management of the third stage of labor, routine uterotonics are administered following the separation of placenta and its attachments to minimize bleeding and bleeding related complications as prophylaxis. The first choice as an uterotonic is intravenous oxytocin. Oxytocin's effect starts in 1 minute and it requires a maintenance dose. The effect of oxytocin on the uterus is achieved by rhythmic contraction of the upper uterine segment. Oxytocin has a half-life of approximately 3 minutes and is metabolized by renal and hepatic routes.

Carbetocin (octapeptide) is a long-acting synthetic analogue of oxytocin (nonapeptide) and administered only as a single dose unlike oxytocin. ${ }^{5}$ It selectively binds to oxytocin receptors in uterine smooth muscles resulting in rhythmic contractions, increased frequency of existing contractions, and increased uterine tone. After administration of carbetocin, uterine contractions start rapidly and a full

\section{Correspondence: Ali GÜRSOY \\ Department of Obstetrics and Gynecology, Maltepe University Faculty of Medicine, İstanbul, TURKEY \\ E-mail: aligursoy@maltepe.edu.tr}

Peer review under responsibility of Journal of Clinical Obstetrics \& Gynecology. 
contraction is achieved within 2 minutes. In case of persistent uterine hypotonia or atony, uterotonic therapy with oxytocin and ergometrine is additionally added to increase tone. The terminal half-life elimination is approximately 40 minutes. Since carbetocin's uterotonic activity persists for several hours after a single bolus injection, it is not suitable for use at any stage before delivery. Although, carbetocin has been shown to pass into breast milk following a single bolus dose, it has been shown to be eliminated in the baby's intestines so it can be used safely. ${ }^{6}$

The aims of the study were to compare the haemodynamic effects of oxytocin and carbetocin and also to evaluate in terms of changes in hemoglobin level, hematocrit level, effects on urine output, blood transfusion requirement, hospital stay, postoperative fever, and need for peripartum hysterectomy.

\section{MATERIAL AND METHODS}

The study was carried out retrospectively by scanning patient files. Until 2016, oxytocin was used in cesarean operations to increase uterine tone. After this date, carbetocin was also started to be used for uterotonic purpose.

The women giving birth by cesarean section between January 2016 and April 2017 were divided into two groups according to the uterotonic administration; carbetocin or oxytocin. Pregnant with singleton fetus $>37^{\text {th }}$ week and patients giving birth with regional anesthesia were included in the study. Since carbetocin was only approved for use in regional anesthesia, it was not administered to patients undergoing general anesthesia.

The exclusion criteria are set out in Table 1 . Since patients with a high risk of PPH were excluded from the study, there is no patient group that can cause bias in the selection of the carbetocin and oxytocin groups. In both groups; maternal age, gestational week of cesarean section, maternal gravidity, maternal parity, history of previous cesarean section, fetus weight, maternal body mass index, maternal preoperative hemoglobin value, postoperative hemoglobin value, preoperative platelet value, postoperative platelet value and their additional uteronic medication needs in cases where uterine tone cannot be achieved were scanned from the files and transferred to the data form. Also,

\section{TABLE 1: Exclusion criteria.}

- History of postpartum hemorrhage
- Patients with risk factors for postpartum hemorrhage
- Oxytocin and carbetocin usage contraindicated
- <18 years of age
- <37 weeks of gestation
- Multiple pregnancies
- Cesarean section with general anesthesia
- Known coagulation disorders
- Eclamptic pregnant and eclampsia history
-2 or more previous cesarean sections
- History of classical uterine incision
- Presence and suspicion of placenta insertion anomaly
- HELLP syndrome
- Cardiovascular renal hepatic disease
- Epilepsy diagnosis
- Chorioamnionitis diagnosis and suspicion
- Fetal anomaly
- Fetal macrosomia
- Uterine anomaly
- Polyhydramniosis
- Prolonged induction of labor
- Fibroids

vital signs after drug administration and side effects postoperatively observed up to 24 hours were scanned from patient files and recorded in the data form. This research was conducted in accordance with the principles set forth in the Helsinki Declaration 2008 and ethics committee approval was obtained for this study (T.C Maltepe University Clinical Research Ethics Committee No: 2017/900/25, 24.5.2017).

In the oxytocin group "Synpitan forte $5 \mathrm{IU} / \mathrm{mL}$ IM/IV ampoule" (İstanbul, Turkey) was used. Within 1 minute of delivery of the baby, 20 IU oxytocin was administered as an intravenous infusion in $100 \mathrm{cc}$ of saline. Since oxytocin is a short-acting uterotonic agent, subsequent maintenance therapy was initiated after the loading dose. Initially, 10 IU oxytocin in $1,000 \mathrm{~mL}$ saline was administered at postpartum first hour, then $10 \mathrm{IU}$ oxytocin within $1,000 \mathrm{~mL}$ saline solution was administered at a rate of $125 \mathrm{~mL} / \mathrm{h}$. In the carbetocin group "Pabal $100 \mu \mathrm{g} / \mathrm{mL}$ IV ampoule" (Kiel, Germany) containing solution for injection was used. $1 \mathrm{~mL}$ of "Pabal" containing $100 \mu \mathrm{g}$ of carbetocin was administered within 1 minute of delivery of the baby intravenously within 60 seconds by slow infusion. 


\section{STATISTICAL ANALYSIS}

NCSS (Number Cruncher Statistical System) 2007 (Kaysville, Utah, USA) was used for statistical analysis. Descriptive statistical methods (mean, standard deviation, median, frequency, ratio, minimum, maximum) were used for the evaluation of the study data. Student's t-test and Mann-Whitney U test were used for comparison of two groups of variables with normal distribution. Pearson chi-square test, Fisher's exact test and Fisher-Freeman-Halton were used to compare the qualitative data. Significance was evaluated at $\mathrm{p}<0.05$.

\section{RESULTS}

This study was conducted with 120 female patients who were eligible for the study. When the demographic characteristics were examined, it was determined that mean gestational weeks at birth was 38 weeks 6 days \pm 6 days and mean birth weight of the fetus was 3,458.38 \pm 404.50 grams. Maternal body mass index measurements ranged from 20.9 to 40.57 $\mathrm{kg} / \mathrm{m}^{2}$, with an average of $29.38 \pm 4.28 \mathrm{~kg} / \mathrm{m}^{2}$ (Table 2). No additional uterotonic requirement was observed in $85 \%(n=102)$ while additional uterotonic requirement was observed in $15 \%(n=18)$ of the cases. Calculated estimated blood loss (cEBL) which is another parameter used in the $\mathrm{PPH}$, is calculated with the formula: ${ }^{\text {? }}$

1. Calculated pregnancy blood volume $=" 0.75$ [maternal height (inches) (x) 50]+ [maternal weight in pounds (x) 25]"

2. Percent of blood volume lost $=$ (Predelivery Hctpostdelivery Hct)/predelivery Hct.

3. $c E B L=$ Calculated pregnancy blood volumexPercent of blood volume lost.

cEBL ranged from $140 \mathrm{~mL}$ to $1,875 \mathrm{~mL}$, with an average of $592.13 \pm 347.69 \mathrm{~mL}$. The ratio of cEBL $\geq 500$ $\mathrm{mL}$ were $59.2 \%(\mathrm{n}=71)$, while those with $\geq 1,000 \mathrm{~mL}$ were $12.5 \%(\mathrm{n}=15)$ (Table 2$)$.

\begin{tabular}{|c|c|c|c|}
\hline & & Minimum-Maximum (Median) & Mean $\pm S D$ \\
\hline Maternal age at birth (year) & & $24-42(32)$ & $32.45 \pm 3.94$ \\
\hline Pregnancy week at birth & & 37-41 (38W5D) & $38 \mathrm{~W} 6 \mathrm{D} \pm 6 \mathrm{D}$ \\
\hline Fetus birth weight (g) & & $2,510-4,485(3,450)$ & $3,458.38 \pm 404.50$ \\
\hline Maternal BMl at birth & & $20.9-40.57(29.01)$ & $29.38 \pm 4.28$ \\
\hline \multirow[t]{2}{*}{ Estimated blood loss (mL) } & & $140-1,875(580)$ & $592.13 \pm 347.69$ \\
\hline & & $\mathrm{n}$ & $\%$ \\
\hline \multirow[t]{4}{*}{ Gravidity } & Gravida 1 & 62 & 51.7 \\
\hline & Gravida 2 & 41 & 34.2 \\
\hline & Gravida 3 & 13 & 10.8 \\
\hline & Gravida 4 & 4 & 3.3 \\
\hline \multirow[t]{4}{*}{ Parity } & Para 0 & 73 & 60.8 \\
\hline & Para 1 & 41 & 34.2 \\
\hline & Para 2 & 5 & 4.2 \\
\hline & Para 3 & 1 & 0.8 \\
\hline \multirow[t]{2}{*}{ Previous cesarean section } & No & 76 & 63.3 \\
\hline & Yes & 44 & 36.7 \\
\hline \multirow[t]{2}{*}{ Additional uterotonic need } & No & 18 & 15.0 \\
\hline & Yes & 102 & 85.0 \\
\hline \multirow[t]{2}{*}{ Blood loss } & $<500 \mathrm{~m}$ & 49 & 40.8 \\
\hline & $\geq 500 \mathrm{~m}$ & 71 & 59.2 \\
\hline \multirow[t]{2}{*}{ Blood loss } & $<1,000 \mathrm{~mL}$ & 105 & 87.5 \\
\hline & $\geq 1,000 \mathrm{~mL}$ & 15 & 12.5 \\
\hline \multirow[t]{2}{*}{ Used medicine } & Oxytocin & 78 & 65.0 \\
\hline & Carbetocin & 42 & 35.0 \\
\hline
\end{tabular}

SD: Standard deviation; BMI: Body mass index. 


\begin{tabular}{|c|c|c|c|c|}
\hline & & Oxytocin $(n=78)$ & Carbetocin (n=42) & $p$ value \\
\hline \multirow[t]{2}{*}{ Maternal age at birth (year) } & Minimum-Maximum (Median) & $24-41(33)$ & $24-42(32)$ & $t=0.577$ \\
\hline & Mean \pm SD & $32.60 \pm 3.65$ & $32.17 \pm 4.45$ & 0.565 \\
\hline \multirow[t]{2}{*}{ Pregnancy week at birth } & Minimum-Maximum (Median) & $37-41$ (38W5D) & $37-41$ (38W6D) & $z=-0.502$ \\
\hline & Mean $\pm S D$ & $38.77 \pm 0.79$ & $38.94 \pm 1.04$ & b0.615 \\
\hline \multirow[t]{2}{*}{ Fetus birth weight (g) } & Minimum-Maximum (Median) & $2,660-4,380(3,490)$ & $2,510-4,485(3,365)$ & $t=0.852$ \\
\hline & Mean \pm SD & $3,481.47 \pm 381.81$ & $3,415.48 \pm 445.23$ & 0.396 \\
\hline \multirow[t]{3}{*}{ Maternal BMI at birth } & Minimum-Maximum (Median) & $20.9-40.57(29.38)$ & $21.09-39.84(27.77)$ & $t=1.975$ \\
\hline & Mean $\pm S D$ & $29.94 \pm 4.31$ & $28.34 \pm 4.09$ & ${ }^{\mathrm{a}} 0.051$ \\
\hline & & $\mathrm{n}(\%)$ & $\mathrm{n}(\%)$ & \\
\hline \multirow[t]{3}{*}{ Gravidity } & Gravida 1 & $41(52.6)$ & $21(50.0)$ & $x^{2}=1.317$ \\
\hline & Gravida 2 & $28(35.9)$ & $13(31.0)$ & ${ }^{\circ} 0.518$ \\
\hline & Gravida $\geq 3$ & $9(11.5)$ & $8(19.0)$ & \\
\hline \multirow[t]{3}{*}{ Parity } & Para 0 & $48(61.5)$ & $25(59.5)$ & $x^{2}=2.732$ \\
\hline & Para 1 & $28(35.9)$ & $13(31.0)$ & d0.275 \\
\hline & Para $\geq 2$ & $2(2.6)$ & $4(9.5)$ & \\
\hline \multirow[t]{2}{*}{ Previous cesarean section } & No & $51(65.4)$ & $25(59.5)$ & $x^{2}=0.404$ \\
\hline & Yes & $27(34.6)$ & $17(40.5)$ & ${ }^{\circ} 0.525$ \\
\hline
\end{tabular}

aStudent t-test; ${ }^{b}$ Mann-Whitney U test; ' $P$ Pearson chi-square test; ' ${ }^{\mathrm{F}}$ Fisher-Freeman-Halton test; ${ }^{* *} \mathrm{p}<0.01$; SD: Standard deviation; BMI: Body mass index.

As uterotonic drug, $35 \%$ of the patients had carbetocin $(n=42)$ and $65 \%$ had oxytocin $(n=78)$. Demographic characteristics of both groups were similar in terms of maternal age at birth, gestational weeks at birth, fetus weights at birth, maternal body mass index at birth, gravida numbers, parity numbers and previous cesarean history $(\mathrm{p}>0.05)$ (Table 3 ).

cEBL, $24^{\text {th }}$ hour hemoglobin reduction and $24^{\text {th }}$ hour platelet count diminution percentage were significantly lower in the carbetocin group $(\mathrm{p}=0.044$; $\mathrm{p}=0.042 ; \mathrm{p}=0.004$, respectively) (Figure 1, Figure 2, Figure 3). Over and above, the duration to reach 1,500 cc urine output of carbetocin group was significantly lower than oxytocin $(\mathrm{p}=0.001)$ (Figure 4$)$.

No statistically significant difference was found between the additional uterotonic need, the percentage of change in cEBL and the level of loss of $\geq 1,000 \mathrm{~mL}$ ( $>0.05$ ) (Table 3). The rate of blood loss of $\geq 500 \mathrm{~mL}$ was lower but not significantly different in patients receiving carbetocin compared to those using oxytocin $(\mathrm{p}=0.059)$ (Table 4).

When patient observation notes were examined; rates of nausea, vomiting, tachycardia, flushing, headache, chills, dyspnea and metallic taste did not show statistically significant difference according to the type of drug used ( $p>0.05$ ). Only abdominal pain was found to

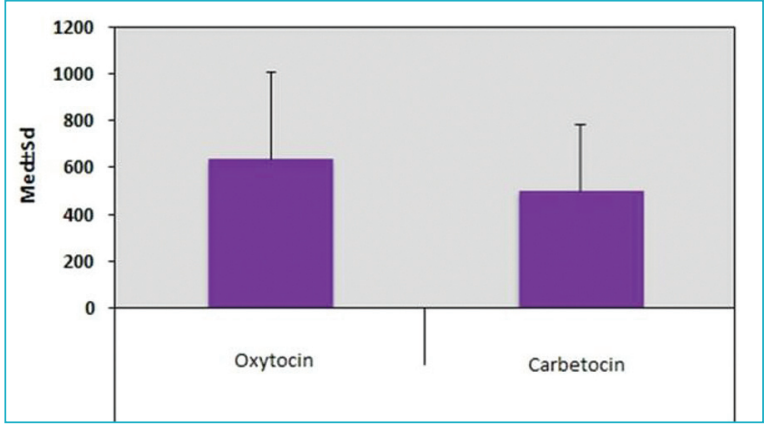

FIGURE 1: Calculated estimated blood loss. SD: Standard deviation.

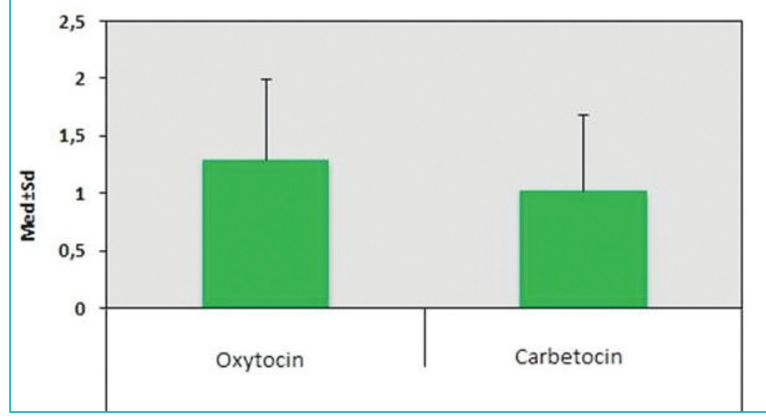

FIGURE 2: 24 hour hemoglobin decrease.

SD: Standard deviation.

be significantly higher in the carbetocin group $(\mathrm{p}=0.036)$ (Table 5). There was no statistically significant difference in systolic blood pressure, diastolic blood pressure and heart rates after 10-20-30-60 minutes ( $p>0.05$ ). 


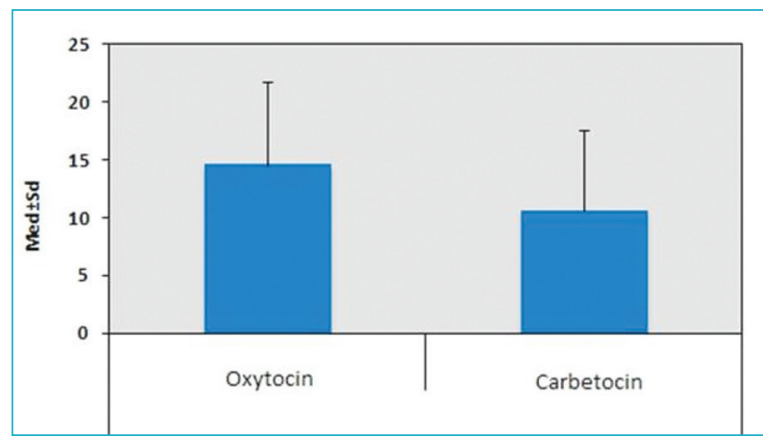

FIGURE 3: 24 hour platelet decrease.

SD: Standard deviation.

\section{DISCUSSION}

Oxytocin is the most used uterotonic drug for the prevention and treatment of PPH. According to the 2018 Canadian and 2018 German guideline, carbetocin is recommended to prevent $\mathrm{PPH}$ for cesarean delivery as the first-line treatment. ${ }^{8}$

As the primary outcome, we evaluated the difference between preoperative and postoperative hemoglobin levels and the difference between preoperative and postoperative hematocrit levels. Besides, uterotonic need, urine output and side effects were evaluated as the secondary outcomes.

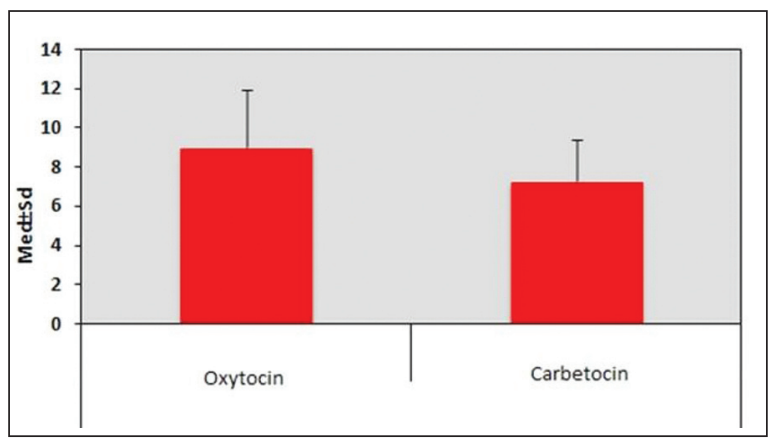

FIGURE 4: Duration of 1,500 cc diuresis (hour). SD: Standard deviation.

The most important parameter to evaluate the effectiveness of uterotonics is the amount of bleeding predicted by the hemoglobin decline rate and cEBL. By comparing the preoperative hemoglobin value versus the amount of hemoglobin on the first postoperative day, we can predict the amount of bleeding according to the difference. Many studies did not find a statistically significant difference between the oxytocin and carbetocin group in terms of amount of hemoglobin decline..$^{9-14}$ In contrast to the studies mentioned above, the preoperative and postoperative hemoglobin decreases were significantly lower in patients receiving carbetocin compared to those using oxytocin in our study $(\mathrm{p}=0.044)$. In a French-based

\begin{tabular}{|c|c|c|c|c|}
\hline & & $\begin{array}{c}\text { Oxytocin } \\
(n=78)\end{array}$ & $\begin{array}{l}\text { Carbetocin } \\
\qquad(n=42)\end{array}$ & $\mathrm{p}$ value \\
\hline \multirow[t]{2}{*}{ Hemoglobin exchange } & Minimum-Maximum (Median) & $0-3.4(1.3)$ & $0.1-2.6(0.85)$ & $\mathrm{t}=2.035$ \\
\hline & Mean $\pm S D$ & $1.29 \pm 0.71$ & $1.02 \pm 0.67$ & ${ }^{a} 0.044^{*}$ \\
\hline \multirow[t]{2}{*}{ Platelet exchange } & Minimum-Maximum (Median) & $0.61-37.05(13.78)$ & $0.5-22.92(8.83)$ & $\mathrm{t}=2.912$ \\
\hline & Mean $\pm S D$ & $14.53 \pm 7.21$ & $10.55 \pm 7.00$ & ${ }^{\mathrm{a}} 0.004^{* *}$ \\
\hline \multirow[t]{2}{*}{ Diuresis time } & Minimum-Maximum (Median) & $5-18(8)$ & 3-14 (7) & $t=3.333$ \\
\hline & Mean $\pm S D$ & $8.99 \pm 2.96$ & $7.26 \pm 2.14$ & ${ }^{a} 0.001^{* *}$ \\
\hline \multirow[t]{2}{*}{ Blood loss } & Minimum-Maximum (Median) & $15-1,875(645)$ & $14-1,158(464.5)$ & $t=2.051$ \\
\hline & Mean \pm SD & $639.27 \pm 370.59$ & $504.57 \pm 284.39$ & $\mathrm{a} 0.042^{*}$ \\
\hline Variation of estimated blood loss according to & Minimum-Maximum (Median) & $0.27-26.74(11.17)$ & $0.27-18.72(8.45)$ & $\mathrm{t}=1.668$ \\
\hline \multirow[t]{2}{*}{ preoperative blood volume (\%) } & Mean $\pm S D$ & $10.91 \pm 6.03$ & $9.09 \pm 5.03$ & 0.098 \\
\hline & & $n(\%)$ & $n(\%)$ & \\
\hline \multirow[t]{2}{*}{ Additional uterotonic need } & No & $65(83.3)$ & $37(88.1)$ & $x^{2}=0.486$ \\
\hline & Yes & $13(16.7)$ & $5(11.9)$ & ${ }^{\circ} 0.486$ \\
\hline \multirow[t]{2}{*}{ Blood loss } & $<500 \mathrm{~mL}$ & $27(34.6)$ & $22(52.4)$ & $x^{2}=3.566$ \\
\hline & $\geq 500 \mathrm{~mL}$ & $51(65.4)$ & $20(47.6)$ & ${ }^{\circ} 0.059$ \\
\hline \multirow[t]{2}{*}{ Blood loss } & $<1,000 \mathrm{~mL}$ & $66(84.6)$ & $39(92.9)$ & $x^{2}=1.695$ \\
\hline & $\geq 1,000 \mathrm{~mL}$ & $12(15.4)$ & $3(7.1)$ & ${ }^{\circ} 0.193$ \\
\hline
\end{tabular}

SD: Standard deviation; ${ }^{\text {aStudent } t-t e s t ; ~}{ }^{\text {Pearson }}$ chi-square test; ${ }^{*} p<0.05$; * $p<0.01$. 


\begin{tabular}{|c|c|c|c|c|}
\hline & & $\begin{array}{l}\text { Carbetocin } \\
(n=48) n(\%)\end{array}$ & $\begin{array}{c}\text { Oxytocin } \\
(n=72) n(\%)\end{array}$ & $p$ value \\
\hline \multirow[t]{2}{*}{ Nausea } & Yes & $5(10.4)$ & $11(15.3)$ & $x^{2}=0.589$ \\
\hline & No & $43(89.6)$ & $61(84.7)$ & ${ }^{\circ} 0.443$ \\
\hline \multirow[t]{2}{*}{ Vomiting } & Yes & $3(6.3)$ & $5(6.9)$ & $x^{2}=0.022$ \\
\hline & No & $45(93.8)$ & $67(93.1)$ & ${ }^{e} 1.000$ \\
\hline \multirow[t]{2}{*}{ Tachycardia } & Yes & $5(10.4)$ & $12(16.7)$ & $x^{2}=0.925$ \\
\hline & No & $43(89.6)$ & $60(83.3)$ & ${ }^{\circ} 0.336$ \\
\hline \multirow[t]{2}{*}{ Flushing } & Yes & $6(12.5)$ & $9(12.5)$ & $x^{2}=0.000$ \\
\hline & No & $42(87.5)$ & $63(87.5)$ & ${ }^{c} 1.000$ \\
\hline \multirow[t]{2}{*}{ Headache } & Yes & $3(6.3)$ & $5(6.9)$ & $x^{2}=0.022$ \\
\hline & No & $45(93.8)$ & $67(93.1)$ & ${ }^{8} 1.000$ \\
\hline \multirow[t]{2}{*}{ Tremor } & Yes & $3(6.3)$ & $6(8.3)$ & $x^{2}=0.180$ \\
\hline & No & $45(93.8)$ & $66(91.7)$ & ${ }^{e} 0.740$ \\
\hline \multirow[t]{2}{*}{ Dyspnea } & Yes & $0(0.0)$ & $2(2.8)$ & $x^{2}=1.356$ \\
\hline & No & $48(100.0)$ & $70(97.2)$ & ${ }^{\oplus} 0.516$ \\
\hline \multirow[t]{2}{*}{ Abdominal pain } & Yes & $20(41.7)$ & $17(23.6)$ & $x^{2}=4.402$ \\
\hline & No & $28(58.3)$ & $55(76.4)$ & ${ }^{\circ} 0.036$ \\
\hline \multirow[t]{2}{*}{ Metallic taste in mouth } & Yes & $2(4.2)$ & $2(2.8)$ & $x^{2}=0.172$ \\
\hline & No & $46(95.8)$ & $70(97.2)$ & ${ }^{E} 1.000$ \\
\hline
\end{tabular}

'Pearson chi-square test.

study, the amount of hemoglobin decline was lower in the carbetocin group like ours $(\mathrm{p}<0.001) .{ }^{15}$

In the studies of Razali et al. and Attilakos et al., no statistically significant difference was found in terms of cEBL. ${ }^{12,13}$ In our study, cEBL was $504.57 \pm 284.39 \mathrm{~mL}$ in the carbetocin group and $639.27 \pm 370.59 \mathrm{~mL}$ in the oxytocin group $(\mathrm{p}=0.042)$.

Since there is still no consensus on the amount of $\mathrm{PPH}$, the threshold of $500 \mathrm{cc}$ and 1,000 cc bleedings were both observed in our study. When $\geq 500 \mathrm{~mL}$ PPH was observed, Razali et al. reported that this rate was $39 \%$ in the carbetocin group and $36 \%$ in the oxytocin group $(\mathrm{p}=0.47) .{ }^{12}$ In the study of Borruto et al. the rate was $81 \%$ in the oxytocin group and $55 \%$ in the carbetocin group ( $\mathrm{p}=0.05) .{ }^{16}$ According to the Cochrane review, there is evidence that carbetocin (RR $0.72,95 \%$ CI 0.56 to 0.93 , moderate certainty) may reduce $\mathrm{PPH}$ $\geq 500 \mathrm{~mL}$ compared with oxytocin. ${ }^{17}$ In our study, the rate of blood loss $\geq 500 \mathrm{~mL}$ (65.4\%) with oxytocin was higher but not significantly different compared to those using carbetocin $(47.6 \%)(\mathrm{p}=0.059)$.

According to another important parameter which is $\geq 1,000 \mathrm{~mL}$ PPH, we did not dedect any statistically significant difference between the bleeding rates in our study similar to the findings of Whigham, Attilakos and Maged et al..$^{9,13,18}$ On the other hand, in another study, ratio of hemorrhage $\geq 1,000 \mathrm{~mL}$ was found to be $5.4 \%$ (15/276) in the carbetocin group and 3.7\% (10/271) in the oxytocin group $(\mathrm{p}=0.33)$ and this different result attributed to the discontinuation or rapid administration of uterotonic medical treatment for 6 hours postoperatively. ${ }^{12}$

One of the most valuable parameter used to compare the efficacy of uterotonics is the requirement for additional uterotonic drugs. It was shown in several studies that there was no statistically significant difference between the carbetocin and oxytocin groups in terms of additional uterotonic requirement. ${ }^{9-11}$ On the contrary, three studies revealed that the additional uterotonic requirements was $38.8 \%$ $33.5 \%-4.7 \%-6.8 \%$ in the carbetocin group, while it was $57.2 \%-45.5 \%-10.1 \%-13.8 \%$ in the oxytocin group $(\mathrm{p}<=0.001, \mathrm{p}=0.023, \mathrm{p}<0.05, \mathrm{p}=0.0036$ respectively). ${ }^{12-15}$ In our study, as in the studies mentioned earlier, there was no statistically significant difference between the two groups in terms of additional uterotonic requirement $(\mathrm{p}>0.05)$. Common problem of studies is the fact that there was no standardization on the amount of oxytocin applied as uterotonic. For example, the amount of oxytocin ad- 
ministered perioperatively varied between 5 IU and $20 \mathrm{IU}$. We assume that in our study there was less uterotonic requirement due to the use of higher doses of (20 IU) oxytocin perioperatively and therefore the results of both groups were similar.

Oxytocin is known to have antidiuretic activity, even its mechanism is not fully understood. Hyponatremia and water intoxication are among the feared side effects of oxytocin. There are two publications in the literature investigating the antidiuretic activity of carbetocin by comparing it with oxytocin. Larciprete et al. in their study compared carbetocin and oxytocin administered patients with regard to postoperative $12^{\text {th }}$ hour diuresis amount and determined that in the carbetocin group it was $1,300 \mathrm{~mL} \pm 450 \mathrm{~mL}$ and in the oxytocin group was $1,100 \mathrm{~mL} \pm 250 \mathrm{~mL}(\mathrm{p}=0.01) \cdot{ }^{19}$ In the study of De Bonis et al., the amount of diuresis at the postoperative $24^{\text {th }}$ hour was compared and found to be $2,282.36 \pm 81.0 \mathrm{~mL}$ in the carbetocin group and $2,292.9 \pm 82.6 \mathrm{~mL}$ in the oxytocin group. ${ }^{20}$ By examining the patient files, we calculated in how many hours they reached $1,500 \mathrm{cc}$ urine output. In the oxytocin group, it was found to be $8.99 \pm 2.96$ hours and in the carbetocin group it was $7.26 \pm 2.14$ hours. Negative effect on urine output of carbetocin group was significantly lower than oxytocin group $(\mathrm{p}<0.05)$. This effect has a significant advantage for carbetocin and is remarkable.

Although, the decrease of platalets was found to be similar in 2 different studies, we found a statistically significant decrease in oxytocin group $(\mathrm{p}<0.05) .{ }^{10,14} \mathrm{We}$ linked this different result to the high amount of bleeding in the oxytocin group and thus to a decrease in platelet values. In only one study, a patient in the oxytocin group had to undergo a hysterectomy operation due to PPH. ${ }^{12}$ In addition, in a study performed in patients who delivered vaginally, a patient in the oxytocin arm required uterus artery ligation and internal iliac artery ligation due to $\mathrm{PPH} .{ }^{18}$ In our study, no additional surgical intervention was required.

One of the most important limitation of drug use is its side effects. Therefore, it is necessary to know the possible side effects of the drug to be used. Oxytocin is known to cause unwanted cardiovascular side effects such as tachycardia, hypotension and electrocardiographic changes. In addition, oxytocin has also been shown to cause nausea, vomiting, tachycardia, flushing, headache, dizziness, chills, metallic taste, dyspnea, palpitations, itching, chest pain, pulmonary edema, severe water intoxication, and convulsions. ${ }^{13,18,21-23}$ We found no significant difference between carbetocin and oxytocin in terms of side effects other than abdominal pain. Abdominal pain was observed in 20/48 patients treated with carbetocin, while it was observed in $17 / 72$ patients treated with oxytocin $(p=0.036)$. We think that this is due to the fact that carbetocin provides stronger uterine contraction than oxytocin. Fatal bronchospasm and bradycardia after carbetocin were described in a case report published by Pérez-Nieto et al. This study suggests avoiding the use of carbetocin in pregnant women with asthma and those with a history of bronchial hyperactivity until further studies are conducted. ${ }^{24}$

According to the results of a randomized clinical study, it was concluded that carbetocin may be a good alternative modality to traditional uterotonic agents such as oxytocin to prevent PPH in patients with cesarean operation under general anesthesia. ${ }^{25}$

Meanwhile, although we used $100 \mu \mathrm{g}$ of carbetocin which was the recommended dose in our study, in a randomized controlled study, patients were given $20,40,60,80$ or $100 \mu \mathrm{g}$ doses and PPH amounts were compared. The results of the study showed that 20 $100 \mu \mathrm{g}$ carbetocin doses were similarly effective in women with low PPH risk undergoing elective cesarean delivery. ${ }^{26}$ A meta-analysis made in 2018 shows that although carbetocin is effective in postpartum bleeding, cost-effectiveness analysis should be done before its prophylactic use, since it is expensive compared to other uterotonics. ${ }^{27}$

The limitations of our study can be stated to be its retrospective design and conducted with a small number of samples.

\section{CONCLUSION}

Carbetocin appears to be effective in the hemoglobin reduction, platelet reduction and cEBL. In addition, another advantage of carbetocin is that it has less negative effects on urine output than oxytocin. It is noteworthy that carbetocin administration can prevent PPH in appropriate cases. The use of carbetocin is only valid for the prevention of PPH. There 
are no adequate studies on the use of carbetocin for conditions such as birth induction or PPH treatment like other uterotonics and is not recommended.

\section{Source of Finance}

During this study, no financial or spiritual support was received neither from any pharmaceutical company that has a direct connection with the research subject, nor from a company that provides or produces medical instruments and materials which may negatively affect the evaluation process of this study.

\section{Conflict of Interest}

No conflicts of interest between the authors and / or family members of the scientific and medical committee members or mem- bers of the potential conflicts of interest, counseling, expertise, working conditions, share holding and similar situations in any firm.

\section{Authorship Contributions}

Idea/Concept: Ali Gürsoy, Erdin İlter; Design: Ali Gürsoy, Erdin İlter, Aygen Çelik, Berna Haliloğlu Peker; Control/Supervision: Ali Gürsoy, Erdin Illter; Data Collection and/or Processing: Ali Gürsoy, Erdin İlter, Aygen Çelik, Berna Haliloğlu Peker; Analysis and/or Interpretation: Ali Gürsoy, Kemal Atasayan, Ümit Özekici; Literature Review: Ali Gürsoy, Erdin Ilter; Writing the Article: Ali Gürsoy; Critical Review: Kemal Atasayan, Ümit Özekici, Talat Ercan Şerifsoy; References and Fundings: Ali Gürsoy.

\section{REFERENCES}

1. WHO recommendations: Uterotonics for the prevention of postpartum haemorrhage. Geneva: World Health Organization; 2018. [Pubmed]

2. Committee on Practice Bulletins-Obstetrics. Practice Bulletin No. 183: postpartum hemorrhage. Obstet Gynecol. 2017;130(4):e168-86. [Crossref] [Pubmed]

3. Tunçalp O, Souza JP, Gülmezoglu M; World Health Organization. New WHO recommendations on prevention and treatment of postpartum hemorrhage. Int J Gynaecol Obstet. 2013;123(3):254-6. [Crossref] [Pubmed]

4. Say L, Chou D, Gemmill A, Tunçalp Ö, Moller AB, Daniels J, et al. Global causes of maternal death: a WHO systematic analysis. Lancet Glob Health. 2014;2(6):e323-33. [Crossref] [Pubmed]

5. Sweeney G, Holbrook AM, Levine M, Yip M, Alfredsson K, Cappi S, et al. Pharmacokinetics of carbetocin, a long-acting oxytocin analogue, in nonpregnant women. Current Therapeutic ResearchClinical and Experimental. 1990;47(3):528-40. [Link]

6. Silcox J, Schulz P, Horbay GL, Wassenaar W. Transfer of carbetocin into human breast milk. Obstet Gynecol. 1993;82(3):456-9. [Pubmed]

7. Stafford I, Dildy GA, Clark SL, Belfort MA. Visually estimated and calculated blood loss in vaginal and cesarean delivery. Am J Obstet Gynecol. 2008;199(5):519.e1-7. [Crossref] [Pubmed]

8. Chao YS, McCormack S. Carbetocin for the Prevention of Post-Partum Hemorrhage: A Review of Clinical Effectiveness, Cost-Effectiveness, and Guidelines [Internet]. Ottawa (ON): Canadian Agency for Drugs and Technologies in Health; 2019. [Pubmed]

9. Whigham CA, GorelikA, Loughnan TE, Trivedi A. Carbetocin versus oxytocin to reduce additional uterotonic use at non-elective caesarean section: a double-blind, randomised trial (.). J Matern Fetal Neonatal Med. 2016;29(23):3866-9. [Crossref] [Pubmed]

10. Nucci B, Aya A, Aubry E, Ripart J. Carbetocin for prevention of postcesarean hemorrhage in women with severe preeclampsia: a before-after cohort comparison with oxytocin. J Clin Anesth. 2016;35:321-5. [Crossref] [Pubmed]

11. Moertl MG, Friedrich S, Kraschl J, Wadsack C, Lang $U$, Schlembach D. Haemodynamic effects of carbe- tocin and oxytocin given as intravenous bolus on women undergoing caesarean delivery: a randomised trial. BJOG. 2011;118(11):1349-56. Erratum in: BJOG. 2011;118(12):1549. [Crossref] [Pubmed]

12. Razali N, Md Latar IL, Chan YK, Omar SZ, Tan PC. Carbetocin compared to oxytocin in emergency cesarean section: a randomized trial. Eur J Obstet Gynecol Reprod Biol. 2016;198:35-9. [Crossref] [Pubmed]

13. Attilakos G, Psaroudakis D, Ash J, Buchanan R, Winter $C$, Donald $F$, et al. Carbetocin versus oxytocin for the prevention of postpartum haemorrhage following caesarean section: the results of a double-blind randomised trial. BJOG. 2010;117(8):929-36. [Crossref] [Pubmed]

14. Dansereau J, Joshi AK, Helewa ME, Doran TA, Lange IR, Luther ER, et al. Double-blind comparison of carbetocin versus oxytocin in prevention of uterine atony after cesarean section. Am J Obstet Gynecol. 1999;180(3 Pt 1):670-6. [Crossref] [Pubmed]

15. Pizzagalli F, Agasse J, Marpeau L. Comparaison entre carbétocine et oxytocine en cours de césarienne dans la prévention des hémorragies du postpartum [Carbetocin versus Oxytocin during caesarean section for preventing postpartum haemorrhage]. Gynecol Obstet Fertil. 2015;43(5):356-60. French. [Crossref] [Pubmed]

16. Borruto F, Treisser A, Comparetto C. Utilization of carbetocin for prevention of postpartum hemorrhage after cesarean section: a randomized clinical trial. Arch Gynecol Obstet. 2009;280(5):707-12. [Crossref] [Pubmed]

17. Gallos ID, Papadopoulou A, Man R, Athanasopoulos $\mathrm{N}$, Tobias A, Price MJ, et al. Uterotonic agents for preventing postpartum haemorrhage: a network meta-analysis. Cochrane Database Syst Rev. 2018;12(12): CD011689. [Crossref] [Pubmed] [PMC]

18. Maged AM, Hassan AM, Shehata NA. Carbetocin versus oxytocin in the management of atonic post partum haemorrhage (PPH) after vaginal delivery: a randomised controlled trial. Arch Gynecol Obstet. 2016;293(5):993-9. [Crossref] [Pubmed]

19. Larciprete G, Montagnoli C, Frigo M, Panetta V, Todde C, Zuppani B, et al. Carbetocin versus oxytocin in caesarean section with high risk of post-partum haemorrhage. J Prenat Med. 2013;7(1):12-8. [Pubmed] [PMC]
20. De Bonis M, Torricelli M, Leoni L, Berti P, Ciani V, Puzzutiello R, et al. Carbetocin versus oxytocin after caesarean section: similar efficacy but reduced pain perception in women with high risk of postpartum haemorrhage. J Matern Fetal Neonatal Med. 2012;25(6):732-5. [Crossref] [Pubmed]

21. Bhattacharya S, Ghosh S, Ray D, Mallik S, Laha A. Oxytocin administration during cesarean delivery: Randomized controlled trial to compare intravenous bolus with intravenous infusion regimen. J Anaesthesiol Clin Pharmacol. 2013;29(1):32-5. [Crossref] [Pubmed] [PMC]

22. Gizzo S, Patrelli TS, Gangi SD, Carrozzini M, Saccardi $\mathrm{C}$, Zambon A, et al. Which uterotonic is better to prevent the postpartum hemorrhage? Latest news in terms of clinical efficacy, side effects, and contraindications: a systematic review. Reprod Sci. 2013;20(9):1011-9. [Crossref] [Pubmed]

23. Mannaerts D, Van der Veeken L, Coppejans $H$ Jacquemyn Y. Adverse effects of carbetocin versus oxytocin in the prevention of postpartum haemorrhage after caesarean section: a randomized controlled trial. J Pregnancy. 2018;2018:1374150. [Crossref] [Pubmed] [PMC]

24. Pérez-Nieto OR, Casta-ón-González JA, LimaLucero IM, Delsol LAG. Near fatal bronchospasm and bradycardia after carbetocin administration. Med Intensiva. 2018;42(5):319-21. [Crossref] [Pubmed]

25. Taheripanah R, Shoman A, Karimzadeh MA, Zamaniyan M, Malih N. Efficacy of oxytocin versus carbetocin in prevention of postpartum hemorrhage after cesarean section under general anesthesia: a prospective randomized clinical trial. J Matern Fetal Neonatal Med. 2018;31(21):2807-12. [Crossref] [Pubmed]

26. Anandakrishnan S, Balki M, Farine D, Seaward G, Carvalho JC. Carbetocin at elective Cesarean delivery: a randomized controlled trial to determine the effective dose, part 2. Can J Anaesth. 2013;60(11):1054-60. [Crossref] [Pubmed]

27. Jin B, Du Y, Zhang F, Zhang K, Wang L, Cui L. Carbetocin for the prevention of postpartum hemorrhage: a systematic review and meta-analysis of randomized controlled trials. J Matern Fetal Neonatal Med. 2016;29(3):400-7. [Crossref] [Pubmed] 